\title{
RATIONAL DESIGN, SYNTHESIS AND CHARACTERIZATION OF HYBRID MOLECULES WITH PYRAZOLINE, PYRIMIDINE AND THIAZOLIDINE NUCLEI AS POTENTIAL ANTIBACTERIAL AGENTS
}

\author{
Liliana Rocio Guerrero-Villalobos, ${ }^{1}$ Fabián Orozco-López ${ }^{2}$
}

\begin{abstract}
In this paper, a set of computational tools were used to design and evaluate molecular structures resulting from the combination of the biologically interesting pyrazoline, aminopyrimidine and thiazolidine nuclei (molecular modification) to obtain new bioactive compounds. Key physicochemical properties were calculated (absorption, distribution, metabolism, excretion and toxicity), to determine the bioavailability of the designed compounds and to perform a preselection of 12 derivatives which were then optimized and studied by molecular docking with the receptor PBP3 (4bjp) from Escherichia coli. By these studies, 8 compounds were selected by their binding energies (from $-5,36 \mathrm{KJ} / \mathrm{mol}$ to $-7,05 \mathrm{KJ} / \mathrm{mol}$ ) and significant interactions with the amino acids of the receptor in its active site. In general, the synthesis of the selected compounds was carried out from the $\alpha, \beta$-unsaturated carbonyl compounds as precursors. The dihydropyrazole derivatives were obtained from the reaction of chalcones with one equivalent of hydrazine derivatives by one-step cyclocondensations. The pyrimidine series were synthesized starting by the reaction of chalcones and guanidine, giving rise to the corresponding amonopyrimidines, which were then reacted with aromatic and heteroaromatic aldehydes to obtain the acyclic azomethine compounds. The thiazolidine-4-ones were obtained from the aminopyrimidines synthesized above, using three-component cyclocondensation reactions with 2-mercaptoacetic acid and benzaldehyde, in anhydrous toluene or benzene as solvents and using conditions of reflux with Dean- Stark. Finally, assays were carried out aiming to the formation of $\beta$-lactam rings, using the Staudinger-type cycloaddition reaction of 2-chloroacetyl chloride with cyclic imines. All the obtained compounds were fully characterized by IR spectroscopy, as well as mono- and bidimensional NMR techniques. The most promising compounds will be evaluated by in vitro assays as potential antibacterial agents.
\end{abstract}

UDC Classification: 547.1; DOI: http://dx.doi.org/10.12955/cbup.v5.1077

Keywords: Antibacterials, molecular modification, virtual screening, pyrazolines, aminopyrimidines, thiazolidines.

\section{Introduction}

The indiscriminate use of antibiotics due to the growing proliferation of bacterial diseases has generated resistant and highly infectious strains that are often fatal in immunocompromised patients (Cuellar, 2013). This has motivated the scientific community to face new challenges in the development of latest introduced compounds with the widest possible spectrum, low toxicity, greater bioactivity and high selectivity.

In addition, the synthetic methods that could be more versatile, economical and practical, implying both health benefits and the generation of new knowledge in the development of pharmacophores of interest (World Health Organization, 2016). This scenario has made it possible to boost the search and discovery of new antimicrobial agents, which is reflected in the long lists of new antibiotic compounds that were not available due to the high amount of research and development in the different areas of both chemistry and medicine, seeking to address the problem (Vardanyan \& Hruby, 2016). Along with this, advances in the understanding of bacterial physiology have established a structure-activity relationship (SAR) (Reguero, Barreto, \& Jimenez, 1989), which has been used to modify the chemical structures of antibiotics with the aim of improving their antimicrobial activity, and thus to fight bacteria that have acquired resistance to previous antimicrobials (Amábile-Cuevas, 2003).

In this field, it is important to mention that the process of developing new medicines can take years to reach its final stage and represent an excellent economic investment to ensure its mechanism of action and guarantee its safety and efficacy in vivo (Marovac, 2001). Consequently, the current trend in obtaining new medicines seeks to rationalize the development of new therapeutic agents based on the relationship between the chemical structure of the medicine and its biological activity, as well as the rational design of new drugs using current tools of computational chemistry which daily grow in their ability to detect unobvious similarities and differences between pharmacotherapeutic agents (Escalona, Carrasco, \& Padrón, 2008).

From this standpoint, the synthesis of heterocyclic compounds is proposed as an alternative to address this problem by means of versatile approaches such as Diversity-Oriented Synthesis - DOS (Spring,

\footnotetext{
${ }^{1}$ National University of Colombia, Bogotá, Colombia, lrguerrerov@unal.edu.co

${ }^{2}$ National University of Colombia, Bogotá, Colombia, forozcol@unal.edu.co
} 
2003), molecular modification or hybrid pharmacophore (Moreno-Díaz, et al., 2008) and bioisosterism (Navarrete-Vázquez, et al., 2006), in order to circumvent the defence mechanisms and thus enhance pharmacological and pharmacodynamic effect of drugs; a process that throughout several studies have shown new and / or better biological activity.

In this respect, this work seeks to apply the methodology of rational in silico drug design with the aim of obtaining molecular prototypes with pyrazole, aminopyrimidine, thiazolidonic and B-lactam nuclei with potential antimicrobial activity; all of them tackled by the derivatization of chalcones as building blocks. In this study, ADMET parameters and virtual screening were considered in order to establish bioavailability and the proper structure-activity relationships, selecting this way the best prototypes to be synthesized by means of computational tools (Cheng et al., 2012), thus contributing to an increase in the chances of success and a decrease in costs (time, infrastructure, experimentation, among others), compared to traditional methods used in the discovery of drugs.

\section{Methods}

a. Structures preparation and virtual screening

Several aspects were taken into account. At the outset, the identification and design of the prototypes to be studied was carried out through the molecular modification approach (hybrid pharmacophore), with the fusion of some nuclei of the different chemical structures of the antibiotics (pyrazolines, aminopyrimidines, thiazolidones and $\beta$-lactams). To establish the best oral bioavailability profile according to the model developed by Lipinski (Lipinski, 2001), 60 new hybrid structures were designed and were then evaluated through in silico studies for the prediction of some relevant ADMET properties. In this study, molecular prototypes (pharmacophoric nuclei) were designed and diversified by the substitutions patterns at the $\mathrm{Ar}$ and $\mathrm{Ar}_{1}$ positions, which sought to enhance biological activity and/or improve their bioavailability (Table 1).

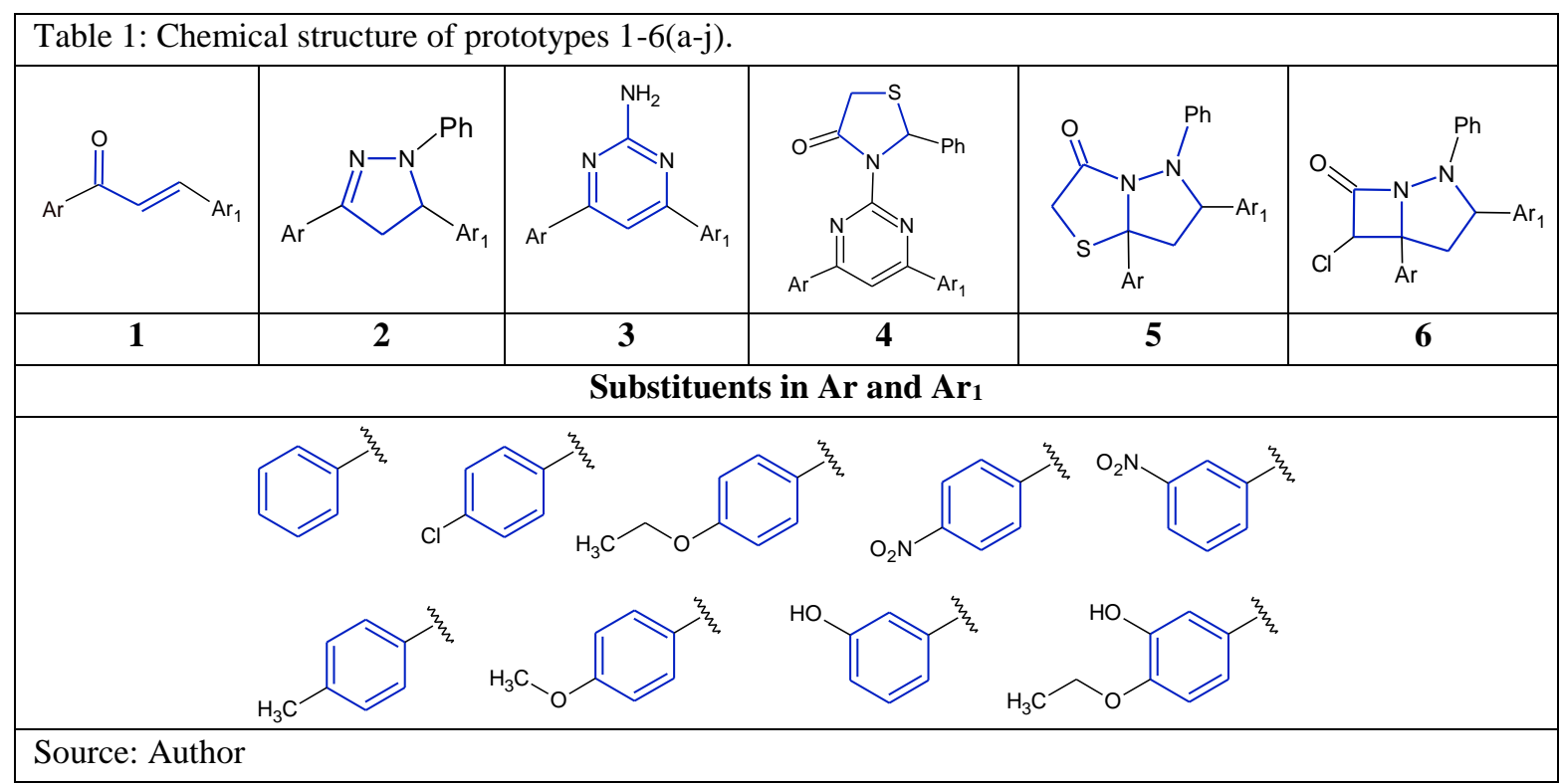

In order to determine the bioavailability and toxicity profile of the prototypes, in silico tools were used that allowed the analysis and subsequent pre-selection of candidate compounds to be studied further. The first source of filtration was the prediction and evaluation of oral absorption from the physicochemical properties (Lipinski's rules) since the more distant they are from the parameters of the rule, the more more complicated to overcome the subsequent stages in a possible development of drugs. Table 2 shows the values of the best prototypes, in which only 5 violates one of Lipinski's rules (lipophilicity), showing an excellent bioavailability profile. Ampicillin was chosen as blank and was therefore subjected to the same process of evaluation of the bioavailability profile used in the other compounds, to compare the values and to analyse the selection criteria of the compounds in each phase. In that sense, it is observed that most of the scores are considerably higher except $\mathbf{5 j}$. 


\begin{tabular}{|c|c|c|c|c|c|c|c|c|}
\hline Compound & $M \log P$ & $\mathrm{~S}+\log P$ & RuleOf5 & RuleOf5_Code & MWt & M_NO & T_PSA & HBDH \\
\hline $\mathbf{1 i}$ & 3.822 & 4.201 & 0 & $\langle$ None $>$ & 282.341 & 3 & 46.53 & 1 \\
\hline $2 g$ & 4.669 & 5.037 & 1 & LP & 358.443 & 4 & 45.06 & 1 \\
\hline $2 \mathrm{j}$ & 4.881 & 5.464 & 1 & LP & 372.47 & 4 & 45.06 & 1 \\
\hline 3d & 4.092 & 4.007 & 0 & $\langle$ None $>$ & 281.746 & 3 & 51.8 & 2 \\
\hline $3 h$ & 3.824 & 4.05 & 0 & $<$ None $>$ & 261.328 & 3 & 51.8 & 2 \\
\hline $4 \mathbf{a}$ & 4.093 & 4.343 & 0 & $<$ None $>$ & 453.566 & 5 & 55.32 & 0 \\
\hline $4 i$ & 3.773 & 4.387 & 0 & $<$ None $>$ & 485.565 & 7 & 95.78 & 2 \\
\hline $4 \mathbf{j}$ & 4.03 & 4.264 & 0 & $<$ None $>$ & 483.592 & 6 & 75.55 & 1 \\
\hline $5 i$ & 4.642 & 4.754 & 1 & LP & 446.571 & 5 & 53.01 & 1 \\
\hline $5 \mathbf{j}$ & 3.678 & 2.831 & 0 & $<$ None $>$ & 310.42 & 3 & 23.55 & 0 \\
\hline $6 \mathbf{a}$ & 6.027 & 4.805 & 1 & LP & 409.318 & 3 & 23.55 & 0 \\
\hline 6c & 5.424 & 5.033 & 1 & LP & 418.926 & 4 & 32.78 & 0 \\
\hline Ampicillin & 0.656 & -1.302 & 0 & $<$ None $>$ & 349.411 & 7 & 112.73 & 4 \\
\hline
\end{tabular}

To predict the toxicity of the prototypes that presented the best bioavailability profiles, the compounds were subjected to estimation of in silico toxicity from their molecular structure using the free online software admetSAR, which is a database that relates structure-activity (Cheng et al., 2012). In general, for toxicity predictions, the entire series of compounds with $-\mathrm{NO}_{2}$ substituents showed toxicity as possible carcinogenic agents and exhibited significant levels of toxicity in environmental, biological models. Compared with Ampicillin, scores for Rat Acute Toxicity $\mathrm{LD}_{50}$ of most of the prototypes resulted similarly, but almost at the limit of the toxicity value, according to the scale of (Hodge \& Sterner, 1949) (From moderately toxic to slightly toxic). The prototype 5i presented the best profile, with the lowest toxicity of the series (Table 3).

With complete ADMET data obtained, it was possible to select the group of molecules to continue to the molecular docking study, since it was necessary to confirm that the potential new drug will be acceptable in terms of efficacy (activity) and safety (Toxicity) for in vitro and in vivo assays in animals and subsequently, in humans.

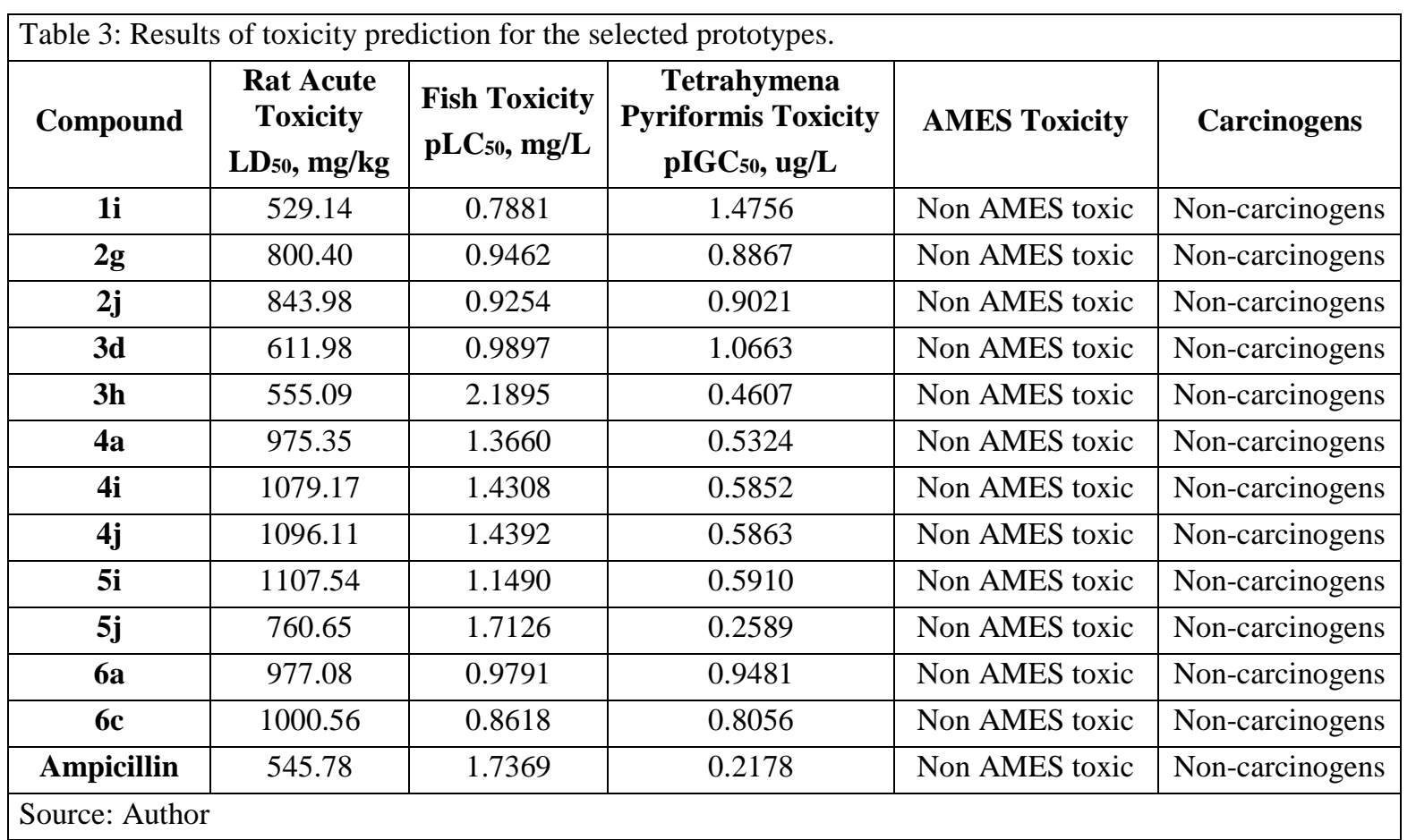


The group comprised of 12 compounds that presented the best bioavailability profiles were subjected to geometric optimization with the help of the HyperChem v.8.0.10 computational tool, in order to find the lowest energy (most stable) molecular conformation for each candidate, which will allow the study of the atomic and molecular properties of the prototypes. With this study, it was possible to establish that 10 of the molecules are below the energy value observed for the reference compound. Only prototypes 6a and $\mathbf{6 c}$ have values close to Ampicillin, indicating that these molecules at the conformational level are the least stable and possibly the most reactive.

\begin{tabular}{|c|c|c|}
\hline \multicolumn{3}{|c|}{ Table 4: Single point energy and gradient of optimized structures of selected prototypes } \\
\hline Compound & Energy $(\mathbf{k c a l} / \mathbf{m o l})$ & Energy Gradient $\mathbf{( k c a l} / \mathbf{m o l})$ \\
\hline $\mathbf{1 i}$ & 16.659472 & 0.009584 \\
\hline $\mathbf{2 g}$ & 12.243122 & 0.009579 \\
\hline $\mathbf{2 j}$ & 12.008585 & 0.009787 \\
\hline $\mathbf{3 d}$ & 27.334485 & 0.009215 \\
\hline $\mathbf{3 h}$ & 21.333536 & 0.009500 \\
\hline $\mathbf{4}^{\mathbf{a}}$ & 30.989200 & 0.009848 \\
\hline $\mathbf{4 i}$ & 31.256056 & 0.009958 \\
\hline $\mathbf{4 j}$ & 33.507793 & 0.009481 \\
\hline $\mathbf{5 i}$ & 28.509365 & 0.008822 \\
\hline $\mathbf{5 j}$ & 25.530389 & 0.009847 \\
\hline $\mathbf{6 a}$ & 88.456739 & 0.009296 \\
\hline $\mathbf{6 c}$ & 89.821765 & 0.009569 \\
\hline Ampicillin & 88.301683 & 0.09338 \\
\hline Source: Author & & \\
\hline
\end{tabular}

With the objective of determining the viability of the interaction of the selected molecules with the catalytic domain of the enzyme transpeptidase PBP3 (4bjp) of E. coli (Berman, et al., 2000), and to find the most likely ligand-receptor binding conformation, the group of compounds were subjected to computer-aided molecular coupling analysis. The study of molecular docking was performed using the computational tool Auto Dock 4.2.6, by a rigid-body approach and study was conducted at the active site identified for the enzyme PBP3 and considering eight key amino acid residues: Ser307, Lys310, Ser359, Asn361, Lys494, Thr495, Gly496 and Thr497, responsible for the binding of Blactams to the active site of PBPs (Sauvage, et al., 2014).

The different Docking results (Table 5), show which of the selected molecules display binding energy values similar to the reference drug Ampicillin $(-6.16 \mathrm{~kJ} / \mathrm{mol})$, and which of them have a better interaction with the amino acids of the catalytic site of the enzyme. In the set of results comprising hydrogen bonds, bonding energies and docking conformations of each of the molecules with the active site, it is evident that the prototypes $1 \mathbf{i}$ and $4 \mathbf{i}$ had interactions with several amino acids in the pocket and which of the atoms of the molecule participate in those bindings. It is also shown that $\mathbf{5 i}$ and $\mathbf{5 j}$ have no apparent interaction in the study.

\begin{tabular}{|c|c|c|c|c|c|}
\hline \multicolumn{2}{|c|}{ Table 5. Binding energies and interactions with active site residues. } \\
\hline Prototype & $\begin{array}{c}\text { Structures } \\
\text { and Hydrogen bonds } \\
\text { (Residue-interaction) }\end{array}$ & $\begin{array}{c}\text { Binding } \\
\text { energy } \\
\text { (kJ/mol) }\end{array}$ & Prototype & $\begin{array}{c}\text { Structures } \\
\text { and Hydrogen bonds } \\
\text { (Residue-interaction) }\end{array}$ & $\begin{array}{c}\text { Binding } \\
\text { energy } \\
\text { (kJ/mol) }\end{array}$ \\
\hline \multirow{5}{*}{$\mathbf{1 i}$} & & & & \\
& & &
\end{tabular}




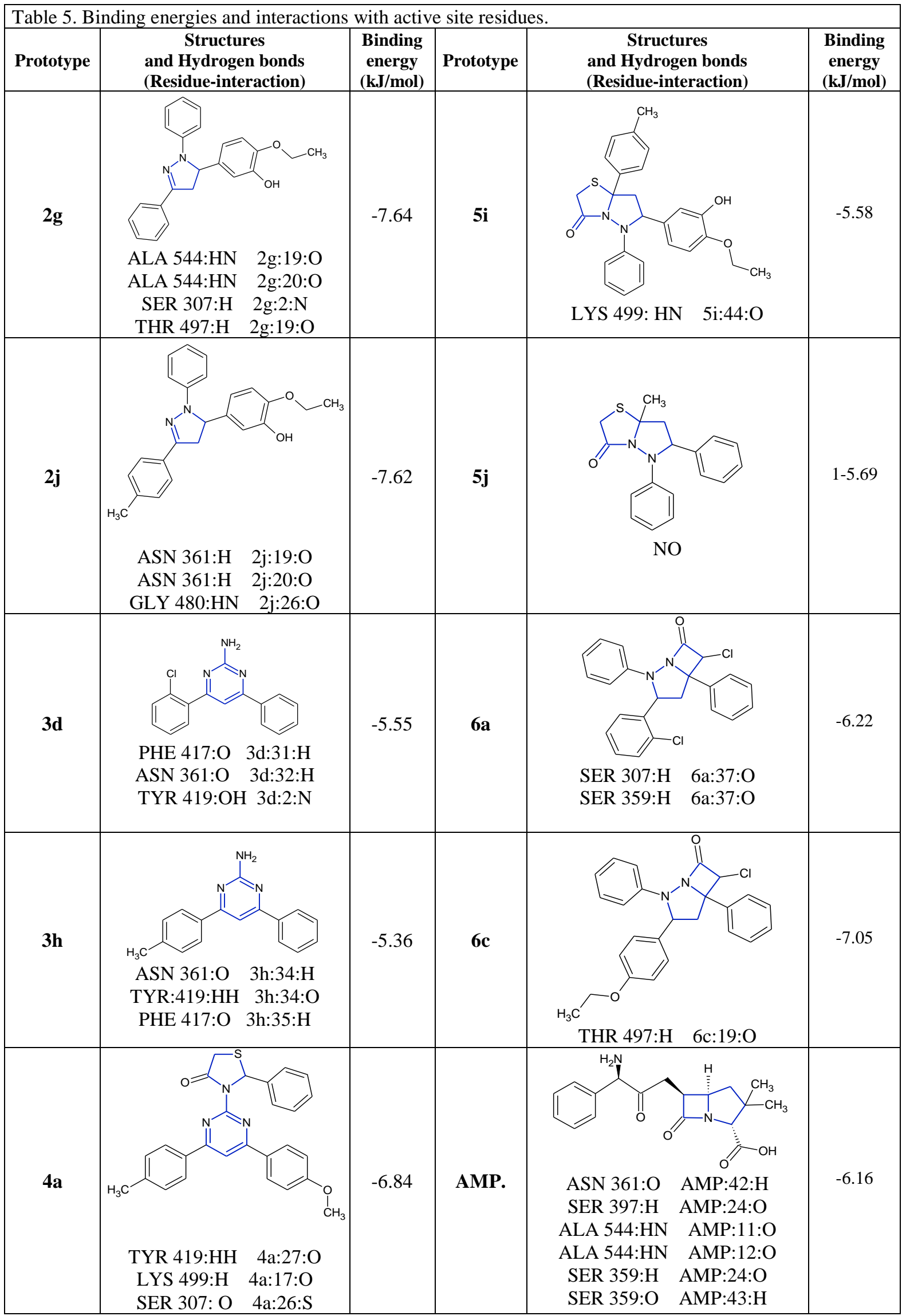




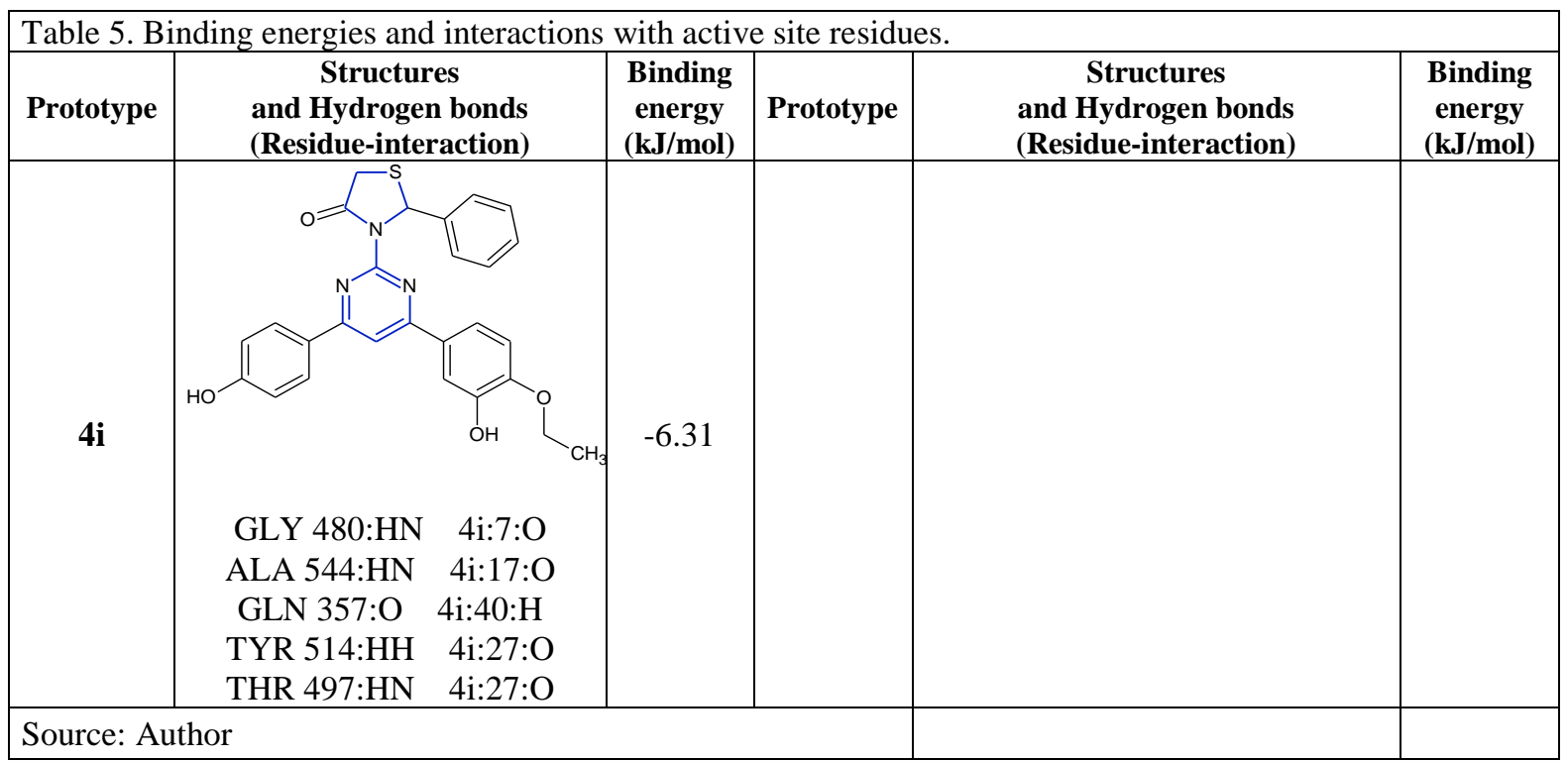

After the enzyme-ligand molecular coupling study, each prototype was visualized and analysed using the PyMOL computational tool (Figure 1), which determined that 10 compounds have interaction with at least one of the residues of the amino acids that are part of the active site of $E$. coli PBP3. Among the compounds that showed interaction with the catalytic site of the enzyme, one is a chalcone (1i), two belong to molecules with pyrazoline nuclei $(\mathbf{2 g}, \mathbf{2 j})$, two to aminopyrimidine derivatives $(\mathbf{3 d}, \mathbf{3 h})$, three to thiazolidone compounds $(\mathbf{4 a}, \mathbf{4 i}, \mathbf{4 j})$ and two to derivatives with $\beta$-lactam nuclei $(\mathbf{6 a}, \mathbf{6 c})$. The last two prototypes are still under consideration to pass to the synthesis stage.

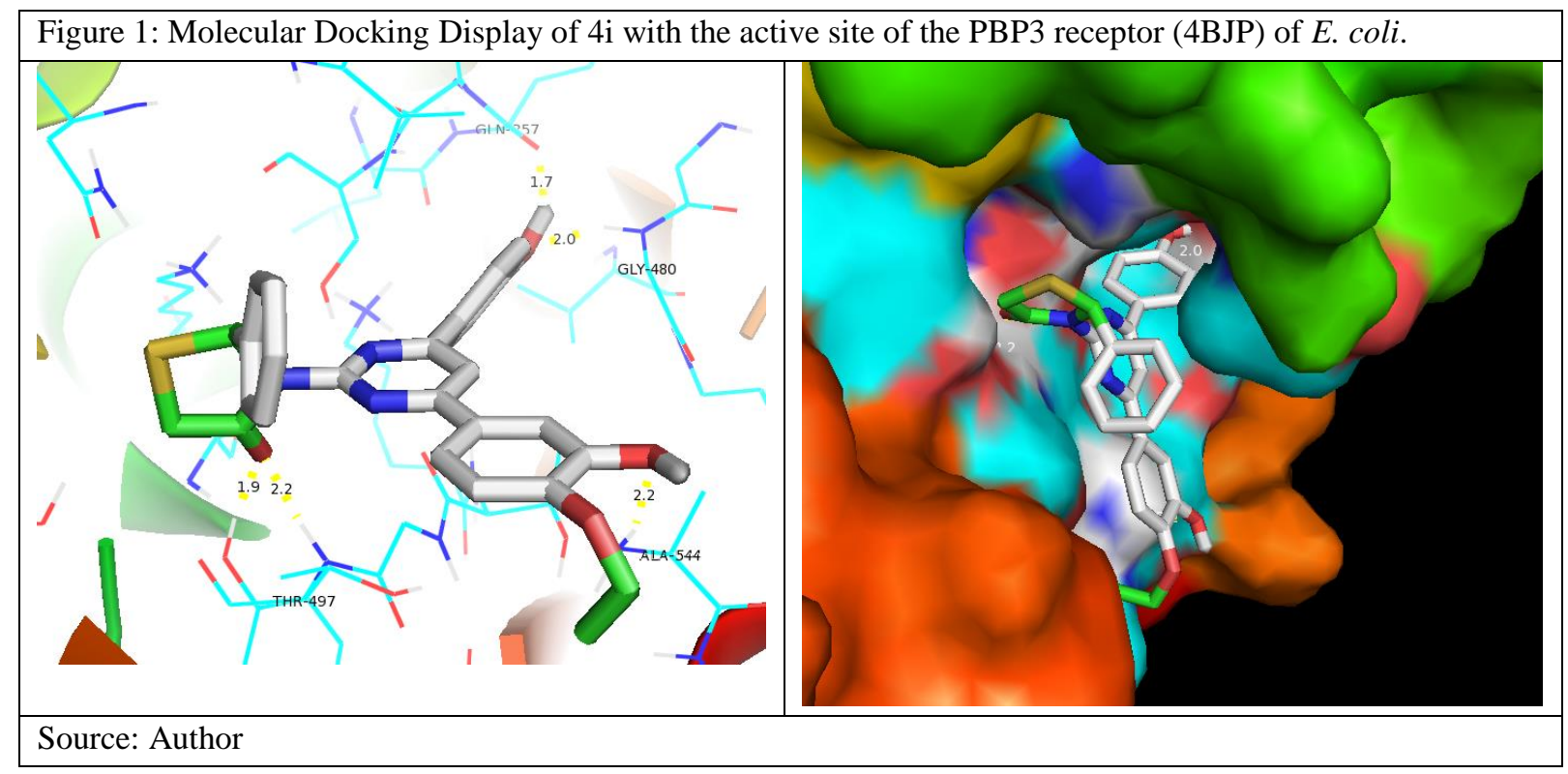

\section{Chemistry}

In general, the synthesis of the selected compounds was carried out in the preparation of $\alpha, \beta$ unsaturated carbonyl compounds as precursors (chalcones), using the Claisen-Schmidt type cyclocondensation reaction between aromatic aldehydes and the corresponding substituted acetophenones, according to the procedure reported in the literature (Durst \& Gokel, 1985). Dihydropyrazole derivatives were obtained from the reaction of chalcones with one equivalent of hydrazine or hydrazine derivatives, by cyclocondensation reactions monitored by TLC. The aminopyrimidine series synthesis was performed by the reaction of chalcones with guanidine to obtain thereby the substituted aminopyrimidine derivatives, which in turn were reacted with aromatic and heteroaromatic aldehydes to obtain the acyclic azomethines. Such as the pyrazolines synthesized, 
aminopyrimidine series exhibited high fluorescence properties in solution, making them interesting because of their potential application in molecular materials science.

Figure 2: General scheme of synthesis of the selected hybrid compounds.

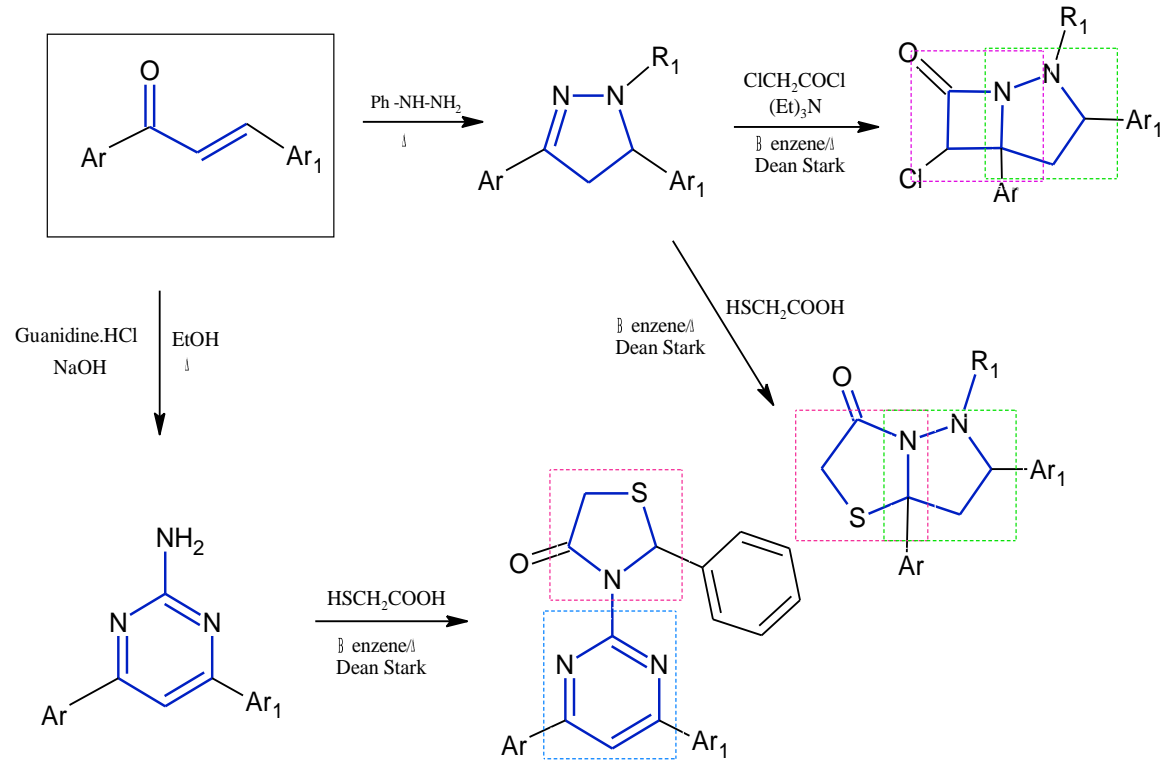

Source: Author

In general, thiazolidine-4-ones were obtained from the aminopyrimidines synthesized above, using three-component cyclocondensation reactions with 2-mercaptoacetic acid and benzaldehyde, in anhydrous toluene or benzene as solvents and using conditions of reflux with Dean- Stark trap. Finally, assays were carried out for the formation of $\beta$-lactam rings, which were conducted using the cycloaddition reaction of 2-chloroacetyl chloride with a cyclic imine, in our particular case pyrazolines. This reaction is known as a Staudinger cycloaddition; however, although many the reaction conditions were used, the desired product could not be obtained, and the pyrazole compound was obtained instead, leading to the conclusion that there is a possible competition between the oxidation reaction (aromatization) and the cycloaddition (formation $\beta$-lactam ring). That is to say that the thermodynamic driving force of the aromatic and more stable pyrazole formation ends up overcoming the formation of the fused $\beta$-lactam ring.

All the obtained compounds were fully characterized and confirmed by IR spectroscopy, ${ }^{1} \mathrm{H}-\mathrm{NMR}$, ${ }^{13} \mathrm{C}-\mathrm{NMR}$ and two-dimensional techniques.

\begin{tabular}{|c|c|c|c|c|c|}
\hline \multicolumn{6}{|c|}{ Table 6: Experimental data of the synthesized compounds } \\
\hline $\begin{array}{c}\text { Compoun } \\
\mathbf{d}\end{array}$ & $\mathrm{Ar}$ & $\mathrm{Ar}_{1}$ & Yield $\%$ & Tf. $\left({ }^{\circ} \mathrm{C}\right)$ & t. Rx (min) \\
\hline $\mathbf{1 i}$ & $-\mathrm{pMe}$ & $-\mathrm{mOH},-\mathrm{pOEt}$ & 92 & $96-98$ & 180 \\
\hline $\mathbf{2 g}$ & $\mathrm{C} 6 \mathrm{H} 5-\mathrm{H}$ & $\mathrm{C} 6 \mathrm{H} 5-\mathrm{mOH},-\mathrm{pOEt}$ & 62 & $196-197$ & 180 \\
\hline $\mathbf{2 j}$ & $\mathrm{C} 6 \mathrm{H} 5-\mathrm{pMe}$ & $\mathrm{C} 6 \mathrm{H} 5-\mathrm{mOH},-\mathrm{pOEt}$ & 58 & $93-95$ & 240 \\
\hline $\mathbf{3 d}$ & $-\mathrm{H}$ & $-\mathrm{oCl}$ & 85 & $62-63$ & 8 \\
\hline $\mathbf{3 h}$ & $-\mathrm{H}$ & $-\mathrm{pMe}$ & 72 & $98-99$ & 12 \\
\hline $\mathbf{4 a}$ & $-\mathrm{pMe}$ & $-\mathrm{pOMe}$ & 18 & $80-82$ & 8 \\
\hline $\mathbf{4 i}$ & $-\mathrm{pOH}$ & $-\mathrm{pOH},-\mathrm{pOEt}$ & 23 & $110-113$ & 25 \\
\hline $\mathbf{4 j}$ & $-\mathrm{pMe}$ & $-\mathrm{pOEt}$ & 22 & $102-104$ & 15 \\
\hline Source: Author & \multicolumn{5}{|l}{} \\
\hline
\end{tabular}




\section{Conclusions}

Following a methodology based on the rational design of in silico drugs, it was possible to propose and study a series of prototypes that have in their structure thiazolidone, aminopyrimidine, pyrazoline and $\beta$-lactam rings. Out of 60 molecules proposed, it was possible to determine that ten exhibited interactions directly with some of the key amino acids that make up the active site of $E$. coli's PBP3 enzyme (4BJP). The ten selected prototypes were considered for synthesis phase, from which eight were obtained and are considered promising hits to be evaluated in subsequent in vitro tests to corroborate the acceptable profile of bioavailability and potential antibacterial activities observed in the computational studies. The series of aminopyrimidine and pyrazoline derivatives presented a characteristic luminescence that could be used for other purposes, such as bioindicators and chemosensors, as well as in molecular materials science.

\section{Acknowledgements}

To the National University of Colombia for the funding and support to carry out this work.

\section{References}

Cheng, F., Li, W., Zhou, Y., Shen, J., Wu, Z., Liu, G., et al. (2012). admetSAR: A Comprehensive Source and Free Tool for Assessment. Journal of Chemical Information and Modeling , 52, 3099-3105.

Lipinski, C. A. (2001). Experimental and computational approaches to estimate solubility and permeability in drug discovery and development settings. Advanced Drug Delivery Reviews , 46, 3-26.

Cuellar, L. E. (2013). Infecciones en huéspedes inmunocomprometidos. Revista Medica Herediana , 24, 156-161.

Amábile-Cuevas, C. (2003). In many ways, the fight against antibiotic resistance is already lost; preventing bacterial disease requires thoughtful new approaches. American Scientist, 91, 138-149.

Berman, H., Westbrook, J., Feng, Z., Gilliland, G., Bhat, T., Weissig, H., et al. (2000). The Protein Data Bank. Retrieved 11 de 10 de 2016 from http://www.rcsb.org/pdb/explore/explore.do?structureId=4BJP

Durst, H. D., \& Gokel, G. W. (1985). Química Orgánica Experimental. Barcelona, España: Reverté S.A.

Escalona, J., Carrasco , R., \& Padrón , J. (2008). Introducción al diseño racional de. Ciudad de la Habana: Editorial Universitaria.

Hodge , H., \& Sterner, J. (1949). Tabulation of toxicity classes. Journal American Industrial Hygiene Association Quarterly, 10, 94-97.

Marovac, J. (2001). Investigación y desarrollo de nuevos medicamentos: de la molécula al farmaco. Revista médica de Chile , 129 (1), 99-106.

Moreno-Díaz, H., Villalobos-Molina, R., Ortiz-Andrade, R., Díaz-Coutiño, D., Medina-Franco, J. L., Webster, S. P., et al. (2008). Antidiabetic activity of N-(6-substituted-1,3-. Bioorganic \& Medicinal Chemistry Letters , 18, 2871-2877.

Navarrete-Vázquez, G., Moreno-Diaz, H., Aguirre-Crespo, F., León-Rivera, I., Villalobos-Molina, R., Muñoz-Muñiz, O., et al. (2006). Design, microwave-assisted synthesis, and spasmolytic activity. Bioorganic \& Medicinal Chemistry Letters , 16, 4169-4173.

Reguero, M., Barreto, E., \& Jimenez, F. (1989). Relacion estructura quimica actividad biológica. Una revisión retrospectiva. Revista Colombiana de de Ciencias Quimico-farmaceuticas , 17, 81-84.

Sauvage, E., Derouaux, A., Fraipont, C., Joris, M., Herman, R., Rocaboy, M., et al. (2014). Crystal Structure of PenicillinBinding Protein 3 (PBP3). PLoS One , 9 (5), 1-11.

Spring, D. (2003). Diversity-oriented synthesis; a challenge for synthetic chemists. Organic \& Biomolecular Chemistry, 1 , 3867-3870.

Vardanyan, R., \& Hruby, V. (2016). Synthesis of Best-Seller Drug. University of Arizona, Tucson, AZ, USA: Academic Press.

World Health Organization. (2016). Antibiotic resistance. Fact sheet. 